\title{
E-BUSINESS PROLIFERATION: INVESTIGATION OF UNDERLYING MECHANISM AND BOUNDARY CONDITION
}

\author{
Shashi Kant Srivastava \\ Jindal Global Business School, Sonipat, India
}

\begin{abstract}
In the last decade, due to the significant spread of the Internet in a society, the e-business is proliferating. In e-business business organizations maximize the use of the Internet for most of their endeavors. However, in many countries such as Macedonia, Seychelles, Serbia, and Lebanon even after good penetration of Internet, e-business is in an early phase and many countries like Indonesia, Cambodia, India, and Senegal even after less penetration of Internet, e-business status is quite good. The objective of this study is to seek the answer to such contradictions. We explore the mechanism through which presence of Internet crowns up in e-business development in a country. We found that innovation capacity and Intellectual Property Protection (IPP) laws of a country features as an underlying mechanism between the relationship of Internet and ebusiness and both variables also work as a boundary condition for the same link. This paper argues that the mere presence of the Internet in a country does not guarantee the development of e-business in that country, rather innovation capacity and IPP are required mediator variables. For robustness analysis, we control the hypothesized equation for per capita income and Human Development Index (HDI) of that country.
\end{abstract}

Keywords: Internet; innovation capacity; intellectual property protection; mediation; moderation 